13

\title{
Интеркаляционный синтез силицидов кобальта под графеном, выращенным на карбиде кремния
}

\author{
(ㄱ Г.С. Гребенюк ${ }^{1}$, И.А. Елисеев ${ }^{1}$, С.П. Лебедев ${ }^{1}$, Е.Ю. Лобанова ${ }^{2}$, Д.А. Смирнов ${ }^{3}$, \\ В.Ю. Давыдов ${ }^{1}$, А.А. Лебедев ${ }^{1}$, И.И. Пронин ${ }^{1, \uparrow}$ \\ ${ }^{1}$ Физико-технический институт им. А.Ф. Иофрфе РАН, \\ Санкт-Петербург, Россия \\ ${ }^{2}$ Университет ИТМО, \\ Санкт-Петербург, Россия \\ ${ }^{3}$ Institute of Solid State Physics, \\ Dresden University of Technology, Dresden, Germany \\ ๑ E-mail: Igor.Pronin@mail.ioffe.ru
}

Поступила в Редакцию 28 октября 2019 г.

В окончательной редакции 28 октября 2019 г.

Принята к публикации 29 октября 2019 г.

Исследован процесс формирования силицидов кобальта в области интерфейса графен-карбид кремния путем интеркалирования кобальтом и кремнием однослойного графена, выращенного на политипах $4 H$ и $6 H-\mathrm{SiC}(0001)$. Эксперименты проведены in situ в условиях сверхвысокого вакуума. Анализ образцов проводился методами фотоэлектронной спектроскопии высокого энергетического разрешения с использованием синхротронного излучения и дифракции медленных электронов, а также методами комбинационного рассеяния света, атомно-силовой и кельвин-зондовой микроскопии. Толщина наносимых слоев кобальта и кремния варьировалась в диапазоне до $2 \mathrm{~nm}$, а температура образцов - от комнатной до $1000^{\circ} \mathrm{C}$. Обнаружено, что атомы Со и $\mathrm{Si}$, нанесенные на нагретые образцы, проникают под графен и локализуются между буферным слоем и подложкой, что приводит к трансформации буферного слоя в дополнительный слой графена. Показано, что результатом интеркалирования системы кобальтом и кремнием является формирование под двухслойным графеном твердого раствора $\mathrm{Co}-\mathrm{Si}$ и силицида $\mathrm{CoSi}$, покрытых поверхностной фазой $\mathrm{Co}_{3} \mathrm{Si}$. Продемонстрирована возможность изменения толщины и состава формируемых силицидных пленок варьированием количества интеркалируемых материалов и очередности их нанесения.

Ключевые слова: графен на карбиде кремния, кобальт, интеркалирование, силициды, фотоэлектронная спектроскопия.

DOI: 10.21883/FTT.2020.03.49014.616

\section{1. Введение}

Благодаря слабому спин-орбитальному взаимодействию и большой длине спиновой релаксации, лежащей в микрометровом диапазоне, графен является перспективным кандидатом для реализации спинового токопереноса. Поскольку спин-поляризованные носители заряда обычно инжектируются в графен из ферромагнетика, граница раздела графен-ферромагнетик вызывает большой интерес исследователей. При этом в области данного интерфейса возникает множество интересных явлений, таких как индуцированный магнетизм, усиленная перпендикулярная магнитная анизотропия, взаимодействие Дзялошинского-Мория и другие [1]. Подавляющее большинство этих явлений было обнаружено для графена, выращенного непосредственно на поверхности металла путем химического осаждения из газовой фазы. Одним из наиболее перспективных альтернативных способов выращивания высококачественного эпитаксиального графена является термодеструкция поверхности монокристаллической подложки карбида кремния [2,3]. Важным преимуществом этого метода является возможность формирования графена на поверхности ком- мерческих подложек $\mathrm{SiC}$ большого диаметра. Для того чтобы получить границу раздела графен-ферромагнетик на подложках карбида кремния, можно использовать интеркаляцию графена магнитными металлами группы железа. На данный момент имеется лишь несколько статей, посвященных проблеме модификации свойств графена, выращенного на $\mathrm{SiC}$, путем интеркалирования ферромагнитными металлами [4-7].

Наряду с металлами группы железа, перспективными материалами для реализации данной задачи являются ферромагнитные силициды $\left(\mathrm{Fe}_{3} \mathrm{Si}, \mathrm{Co}_{3} \mathrm{Si}\right)$ и твердые растворы кремния в металлах. Эти соединения также могут быть синтезированы под графеном методом интеркалирования. В работах $[8,9]$ исследовался процесс интеркалирования кремнием графена, выращенного на эпитаксиальных пленках $\mathrm{Ni}(111), \mathrm{Co}(0001)$ и $\mathrm{Fe}(110)$, сформированных на поверхности вольфрама. Было показано, что нанесение на графен пленок кремния и последующий отжиг образцов позволяют получать силициды металлов группы железа, обладающие разнообразными свойствами. Синтезированные силициды оказались хорошо защищенными графеном от воздействия окружающей среды. При этом сам графен слабо взаимодействует с 
подложкой и находится в квазисвободном состоянии. В более поздних работах $[10,11]$ был предложен двухступенчатый метод интеркаляционного синтеза силицидов железа и кобальта под слоем графена, в котором графен, сформированный на поверхности никеля сначала интеркалируется металлом, а затем кремнием. Это позволяет независимым образом менять содержание металла и кремния в синтезируемой пленке и создавать силициды различного состава.

Что же касается графена на карбиде кремния, к настоящему времени в литературе отсутствуют данные об интеркаляционном синтезе силицидов магнитных металлов в данной системе. В настоящей работе мы попытались восполнить этот пробел. С этой целью мы впервые исследовали процессы интеркалирования графена на карбиде кремния атомами кобальта и кремния, а также эволюцию элементного и химического состава системы с увеличением толщины интеркалированных слоев.

\section{2. Техника эксперимента}

Для получения пленок графена использовался метод термического разложения поверхности $\mathrm{SiC}$. В отличие от работ [12,13], где этот процесс проводился в высоком вакууме, в настоящей работе применялась технология формирования графена в среде инертного газа (аргона) [14]. Она позволяет более точно контролировать процесс сублимации компонентов карбида кремния и путем подбора технологических параметров управлять ростом графеновой пленки. В качестве подложек использовались высокоомные пластины $4 H$ - и $6 H-\mathrm{SiC}(0001)$ размером $5 \times 5 \times 0.3 \mathrm{~mm}$. Условия формирования графена соответствовали конечному этапу оптимизации технологических параметров работы [14].

Для характеризации образцов применялись методы спектроскопии комбинационного рассеяния света (КРС), атомно-силовой (АСМ) и кельвин-зондовой (КЗМ) микроскопии. Измерения методом спектроскопии КРС проводились при комнатной температуре в геометрии „обратного рассеяния“ на спектрометрической установке Horiba Jobin-Yvon T64000, оснащенной конфокальным оптическим микроскопом, который позволяет получать информацию из области графеновой пленки $\sim 1 \mu \mathrm{m}$. Наряду с локальной диагностикой исследовались области размером $10 \times 10 \mu \mathrm{m}$ в центре образцов с последующим построением карт КРС различных параметров спектральных линий. Для возбуждения спектров КРС использовался твердотельный Nd: YAG-лазер $\left(\lambda_{\mathrm{ex}}=532 \mathrm{~nm}\right)$, мощность лазерного излучения на образце равнялась $4.0 \mathrm{~mW}$. Исследование образцов методами АСМ и КЗМ проводились с использованием сканирующего зондового микроскопа Ntegra AURA (NT-MDT).

Процесс синтеза силицидов кобальта под графеном исследовался in situ на Российско-Германском канале вывода синхротронного излучения (СИ) на накопителе HZB BESSY II (г. Берлин). В ходе этих экспериментов на поверхность образцов, нагретых до различных температур, наносились тонкие пленки кобальта и кремния, которые в дальнейшем подвергались 10-минутным отжигам при различных температурах. Толщины нанесенных пленок контролировались кварцевыми микровесами и варьировались в диапазоне до $2 \mathrm{~nm}$. Анализ элементного и химического состава поверхности образцов, а также их атомного строения проводился методами фотоэлектронной спектроскопии (ФЭС) высокого энергетического разрешения с использованием СИ и дифракции медленных электронов (ДМЭ). Регистрация спектров фотоэлектронов проводилась с помощью сверхвысоковакуумного спектрометра PHOIBOS 150 с 200-миллиметровым полусферическим энергоанализатором. Полное энергетическое разрешение прибора (включая разрешение монохроматора) составляло $100 \mathrm{meV}$. Энергия фотонов варьировалась в интервале $135-650 \mathrm{eV}$. Регистрация спектров проводилась при комнатной температуре и давлении остаточных газов $2 \cdot 10^{-10} \mathrm{mbar}$.

\section{3. Результаты и их обсуждение}

\section{1. Характеризация системы графен-карбид кремния}

Экспериментальные данные, иллюстрирующие высокое качество исходных образцов, представлены на
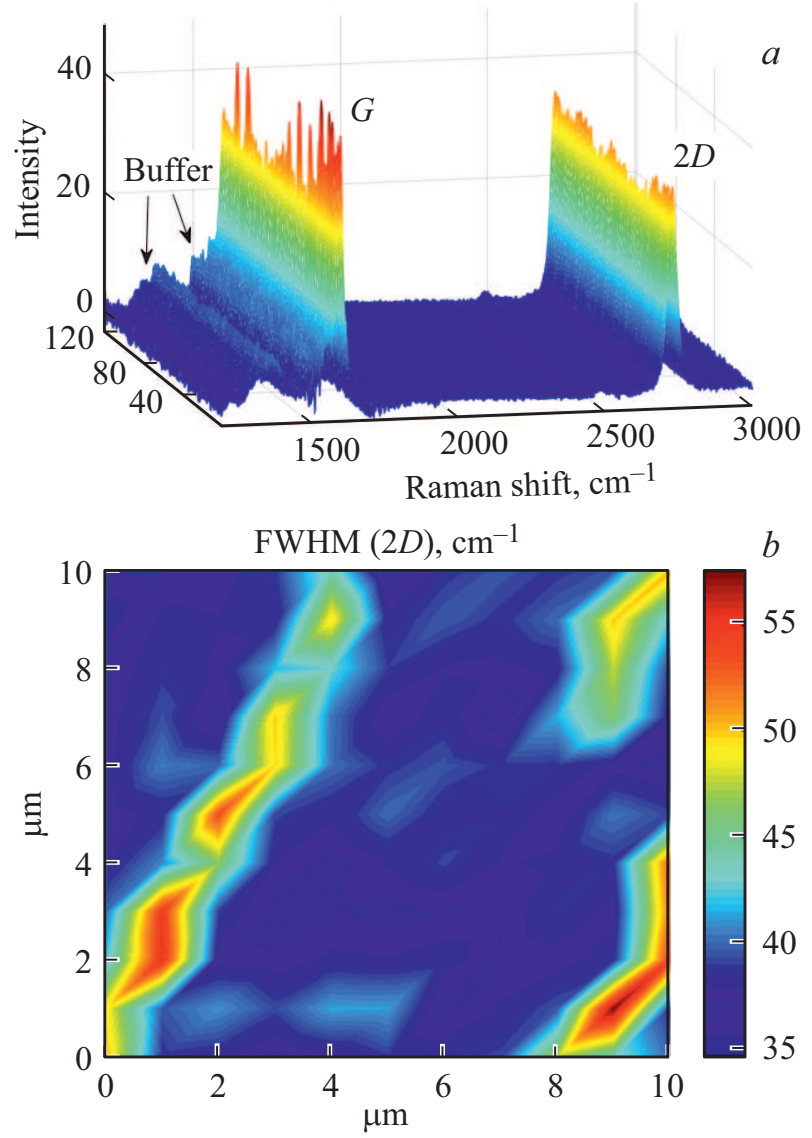

Рис. 1. Массив спектров КРС графена до интеркалирования $(a)$ и карта распределения FWHM линии 2D в исследуемой области $(b)$. 

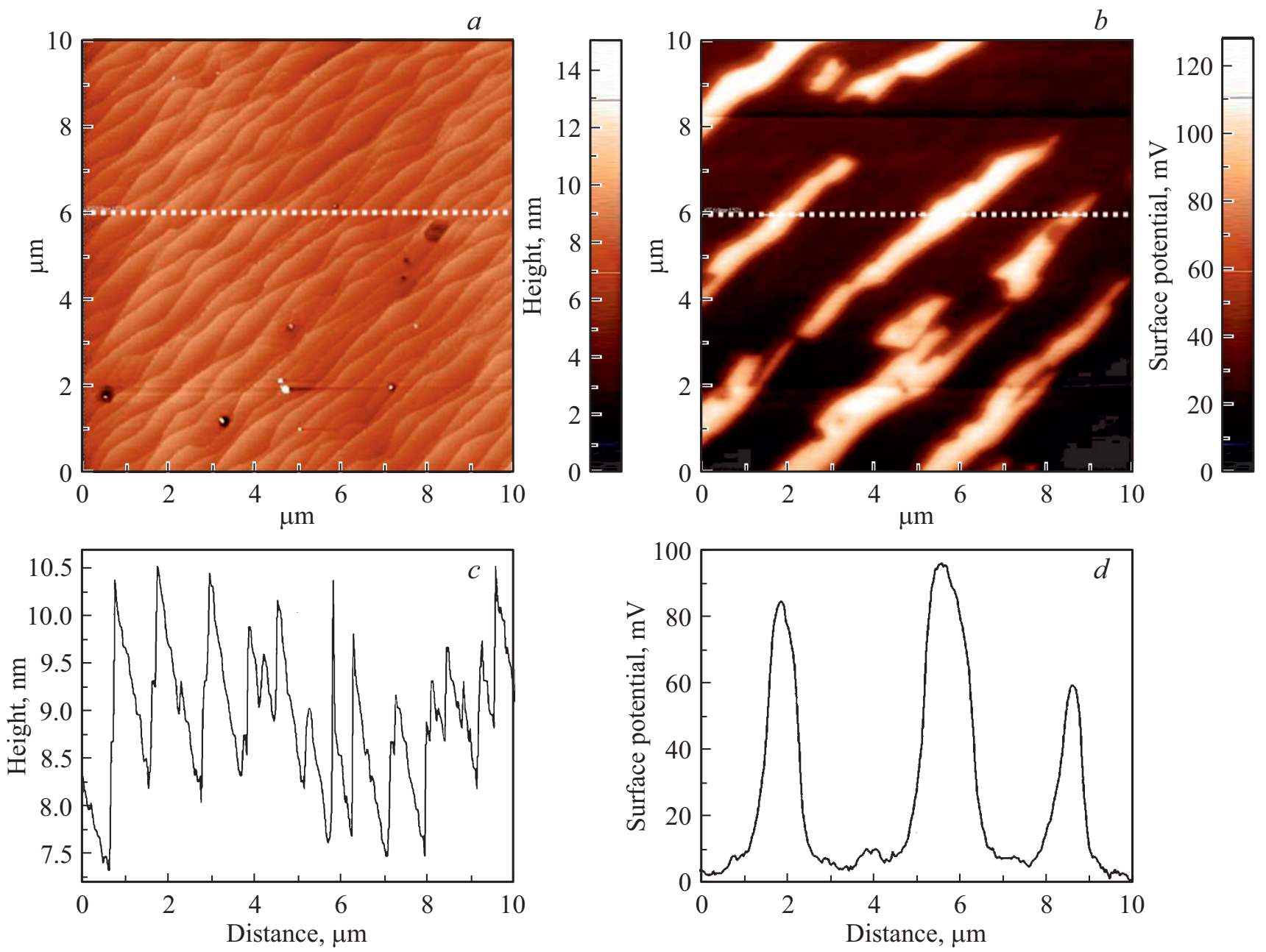

Рис. 2. АСМ-карта (поле $10 \times 10 \mu \mathrm{m})$ топографии поверхности графена на карбиде кремния $(a)$ и ее профиль, измеренный вдоль пунктирной линии $(c)$. КЗМ-карта поверхностного потенциала, полученная в той же области $(b)$ и ее профиль, измеренный вдоль пунктирной линии $(d)$.

рис. 1. Типичный массив спектров КРС, полученный сканированием области $10 \times 10 \mu \mathrm{m}$ в центре образца, показан на рис. 1, $a$. Во всех спектрах имеются линии $G$ и $2 D$, характерные для графена. Кроме того в области $1300-1550 \mathrm{~cm}^{-1}$ наблюдаются также широкие полосы, соответствующие буферному слою, лежащему между графеном и $\mathrm{SiC}$ [15]. Карта распределения полной ширины на половине высоты (FWHM) линии $2 D$, полученная в результате обработки всего массива данных, представлена на рис. $1, b$. В большей части спектров линия $2 D$ имеет симметричную форму, которая хорошо аппроксимируется одиночным контуром Лоренца, а ее ширина составляет около $35 \mathrm{~cm}^{-1}$, что указывает на наличие монослойного графена в соответствующей области [2] (область синего цвета на рис. $1, b)$. В оставшихся спектрах линия $2 D$ имеет асимметричную форму, которая хорошо аппроксимируется огибающей четырех контуров Лоренца, а ее ширина составляет около $50 \mathrm{~cm}^{-1}$. Это говорит о присутствии в исходном образце областей двухслойного графена (участки красного и желтого цвета на рис. $1, b)$. На достаточно высокое качество образца указывает также тот факт, что во всех спектрах массива линию $D\left(\sim 1350 \mathrm{~cm}^{-1}\right)$, возникающую только при наличии дефектов и структурного беспорядка в графене, нельзя выделить из общего фона в виду малости ее интенсивности по сравнению с интенсивностью спектра буферного слоя.

Центральные области образцов, исследовались также методами АСМ и КЗМ. Результаты, полученные с помощью АСМ, представлены на рис. 2, a, c. На нем видны мелкие ступени высотой $1-2 \mathrm{~nm}$. Параметр среднеквадратичного отклонения RMS составляет $0.73 \mathrm{~nm}$. Локальный поверхностный потенциал графеновой пленки зависит от количества монослоев графена. Карта распределения поверхностного потенциала, полученная методом КЗМ, показана на рис. 2, $b$. В ней хорошо видны светлые области. Разность потенциалов между этими участками и темными областями составляет $\sim 100 \mathrm{mV}$, что близко к разности потенциалов между двуслойным и монослойным графеном [16]. Из этого можно сделать 


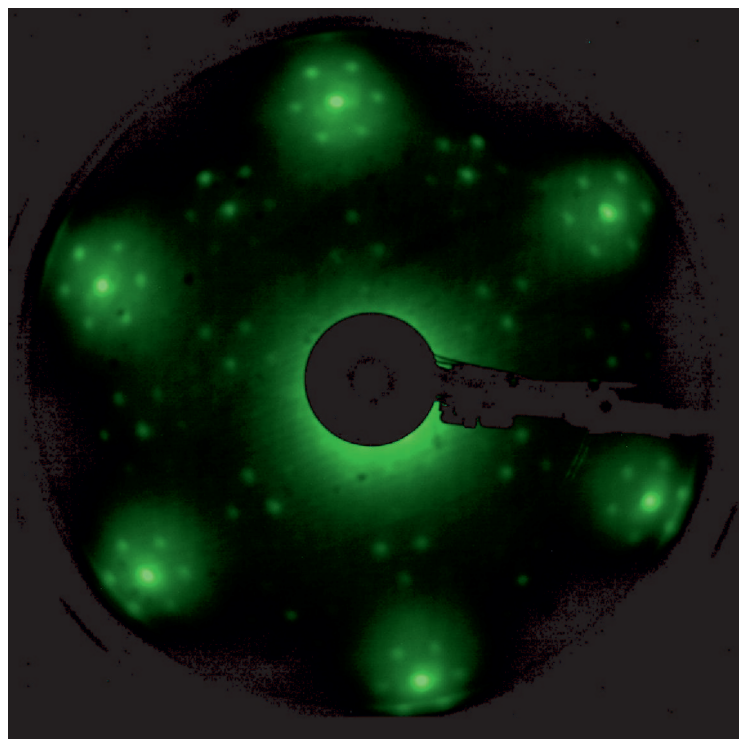

Рис. 3. Картина ДМЭ, полученная при энергии $76.5 \mathrm{eV}$, для образца $\mathrm{Gr} / \mathrm{SiC}$ с чистой поверхностью.

вывод о том, что светлые области на рис. $2, b$, совпадающие по форме и направлению с областями на карте КРС (рис. $1, c)$, соответствуют двухслойному графену, а темные - монослойному. Таким образом, до интеркаляции на поверхности образцов находилась высококачественная преимущественно монослойная графеновая пленка с небольшой долей двухслойных включений.

Типичная картина ДМЭ, наблюдавшаяся после очистки поверхности графена отжигом при $500^{\circ} \mathrm{C}$ в сверхвысоком вакууме, показана на рис. 3. Она была получена при энергии электронов $76.5 \mathrm{eV}$. В ней хорошо видна структура $(6 \sqrt{ } 3 \times 6 \sqrt{ } 3) \times R 30^{\circ}$, характерная для карбида кремния, покрытого однослойным графеном [17]. Структура возникает вследствие несовпадения периодов решеток графена и реконструированной поверхности карбида кремния. Четкость рефлексов картины свидетельствует о строгой упорядоченности кристаллической структуры графена и подложки.

Характерные фотоэлектронные спектры C $1 s$ образца с чистой поверхностью, измеренные при энергии фотонов $470 \mathrm{eV}$ и $650 \mathrm{eV}$, представлены на рис. 4, $a, b$. Они хорошо согласуются с литературными данными для однослойного графена на карбиде кремния $[4,6,14]$. Результаты разложения спектров на составляющие показаны на этом же рисунке. Линия С $1 s$ складывается из четырех компонент. Наиболее интенсивная из них (мода Gr) соответствует графену на поверхности образца. Вторая компонента ( $\mathrm{SiC}$ ) связана с атомами углерода в карбиде кремния. Наконец, моды $S_{1}$ и $S_{2}$ обусловлены наличием двух типов атомов углерода в буферном слое, находящемся между графеном и подложкой $\mathrm{SiC}$. При этом компонента $S_{1}$ соответствует атомам углерода, которые связаны с нижележащим слоем атомов кремния в карбиде кремния, а мода $S_{2}-$ атомам углерода, не связанным с этим слоем. Согласно работе [18] интенсивность моды $S_{2}$ должна быть в два раза больше, чем интенсивность моды $S_{1}$. Как видно из рис. 4, именно такое соотношение интенсивности компонент характерно для приведенных спектров. Сопоставление данных, полученных при двух энергиях фотонов, наглядно демонстрирует более высокую поверхностную чувствительность спектра, соответствующего $470 \mathrm{eV}$ (для которого наблюдается усиление моды графена) по сравнению со спектром, измеренным при энергии $650 \mathrm{eV}$.

\section{2. Исследование интеркалирования системы графен-карбид кремния кобальтом и кремнием in situ}

Данные, иллюстрирующие процесс интеркалирования графена кобальтом при температуре $450^{\circ} \mathrm{C}$, представлены на рис. 4, $c, d$. Влияние температуры подложки на эффективность протекания этого процесса исследовалось в работе [7], где было показано, что именно эта температура является оптимальной. Из рисунка видно, что напыление $0.3 \mathrm{~nm}$ кобальта приводит к заметному ослаблению моды карбида кремния $(\mathrm{SiC})$ относительно моды Gr графена. Это обусловлено тем, что при интеркалировании графена под ним формируется слой кобальта, который поглощает поток фотоэлектронов из $\mathrm{SiC}$ [7].

Эксперименты по напылению кремния на поверхность образцов, находящихся при различных температурах, показали, что интеркалирование графена кремнием протекает при более высоких температурах, чем интеркалирование кобальтом. Так, в отличие от атомов кобальта, атомы кремния не проникают под графен при температуpe $450^{\circ} \mathrm{C}$. Однако, этот процесс становится возможным при данной температуре, если сначала провести интеркалирование графена на карбиде кремния кобальтом. Это демонстрируется спектрами С $1 s$, приведенными на рис. $4, e, f$. Из сопоставления их с данными рис. $4, c, d$ видно, что напыление $0.1 \mathrm{~nm}$ кремния на образец, нагретый до $450^{\circ} \mathrm{C}$, проводимое после интеркалирования графена кобальтом, приводит к дальнейшему ослаблению моды $\mathrm{SiC}$ в спектрах, измеренных при обеих энергиях фотонов, что свидетельствует об интеркалировании графена кремнием.

По мере интеркалирования заметно ослабляются и моды $S_{1}$ и $S_{2}$, соответствующие буферному слою. Они полностью исчезают в спектрах рис. 4 после интеркалирования $0.6 \mathrm{~nm}$ Со и $0.1 \mathrm{~nm} \mathrm{Si}$. Кроме того, в процессе интеркалирования увеличивается абсолютная интенсивность моды графена. Совокупность этих двух факторов свидетельствует о том, что атомы Со и $\mathrm{Si}$ проникают под буферный слой, образуя под ним пленку интеркалируемых веществ. При этом сам буферный слой перестраивается в графен, и таким образом на поверхности образца образуется двухслойный графен. 


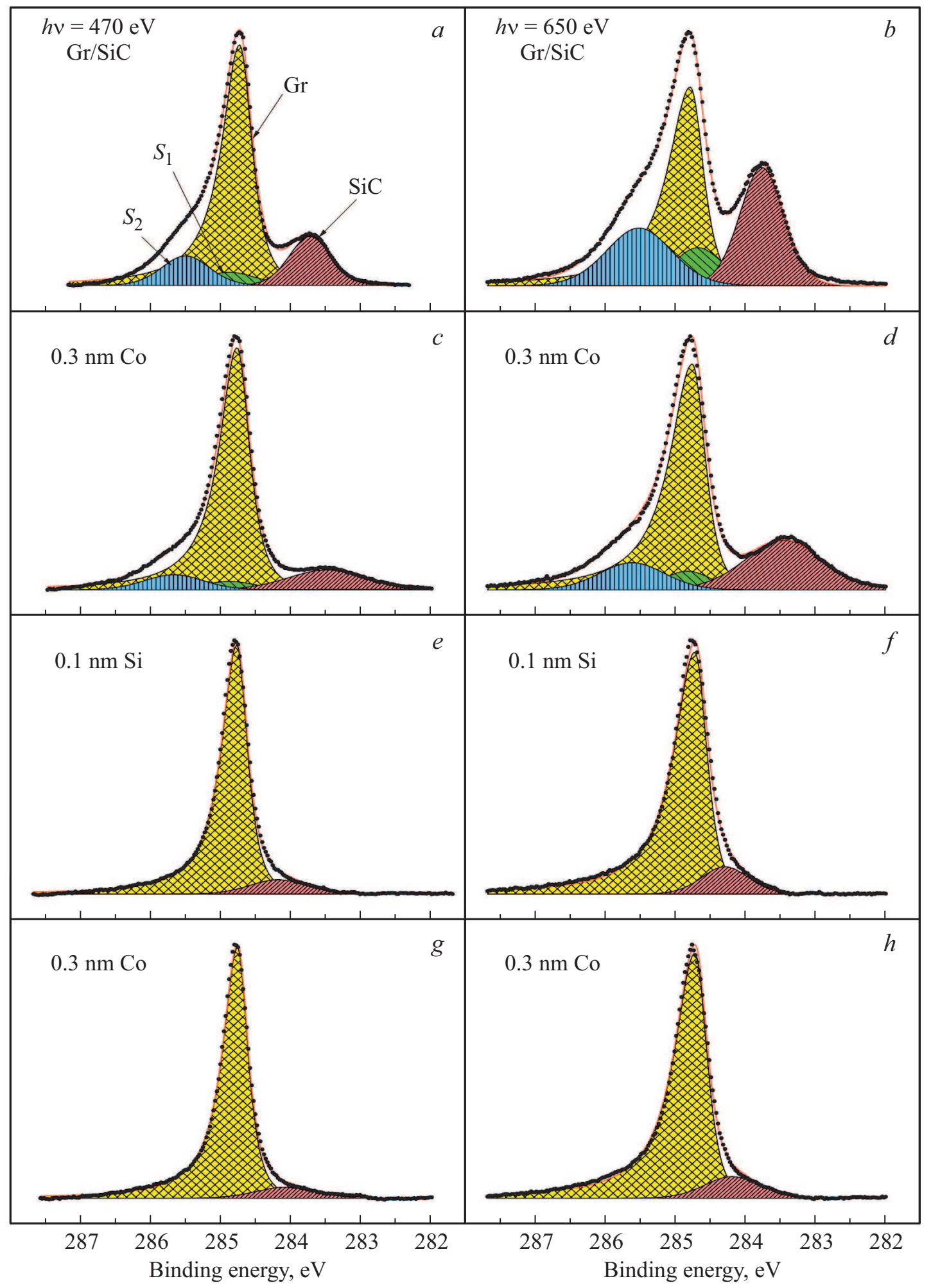

Рис. 4. Спектры C $1 s$, измеренные в ходе интеркалирования графена кобальтом и кремнием при энергиях фотонов 470 и $650 \mathrm{eV}$ а также результаты разложения спектров на составляющие.

Для проверки этого вывода было проведено численное моделирование, основанное на стандартной модели интенсивности фотоэмиссии, широко используемой в количественном анализе поверхности методом ФЭС [19].
Искомые значения толщин были получены с помощью слоистой модели строения образца, в которой на поверхности находится графен, а под ним - буферный слой и подложка $\mathrm{SiC}$. В рамках этой модели интенсивности 
Толщины различных слоев в приповерхностной области, расчитанные на разных стадиях процесса интеркалирования графена кобальтом и кремнием (в $\mathrm{nm})$

\begin{tabular}{l|c|c|c|c|c|c|c}
\hline & $\mathrm{Gr} / \mathrm{SiC}$ & $0.3 \mathrm{~nm} \mathrm{Co}$ & $0.3 \mathrm{~nm} \mathrm{Co}$ & $0.1 \mathrm{~nm} \mathrm{Si}$ & $600^{\circ} \mathrm{C}$ & $0.3 \mathrm{~nm} \mathrm{Co}$ & $850^{\circ} \mathrm{C}$ \\
\hline Graphene & 0.35 & 0.44 & 0.54 & 0.57 & 0.57 & 0.57 & 0.57 \\
Buffer layer & 0.21 & 0.11 & 0.02 & 0.00 & 0.00 & 0.00 & 0.00 \\
Co + Si layer & 0.00 & 0.32 & 0.61 & 0.72 & 0.72 & 1.00 & 1.00
\end{tabular}

мод C $1 s$ спектра от каждого из указанных слоев имеют следующий вид:

$$
\begin{gathered}
I_{g r}=I_{C}^{\infty}\left(1-e^{\frac{-d_{g r}}{\lambda_{C}}}\right), \\
I_{b u f}=I_{C}^{\infty}\left(1-e^{\frac{-d_{b u f}}{\lambda_{C}}}\right) e^{\frac{-d_{g r}}{\lambda_{C}}}, \\
I_{\mathrm{SiC}}=0.5 \cdot I_{C}^{\infty} e^{\frac{-\left(d_{b u f}+d_{g r}\right)}{\lambda_{C}}} e^{\frac{-d_{\mathrm{Co}, \mathrm{Si}}}{\lambda_{\mathrm{Co}, \mathrm{Si}}},}
\end{gathered}
$$

где $I_{C}^{\infty}-$ коэффициент элементной чувствительности углерода, $d_{g r}-$ толщина пленки графена, $d_{b u f}-$ толщина буферного слоя; $d_{\mathrm{Co}, \mathrm{Si}}-$ толщина интеркалированного слоя, $\lambda_{\mathrm{C}}, \lambda_{\mathrm{Co}, \mathrm{Si}}$ - длины свободного пробега фотоэлектронов [20].

Из этих уравнений с помощью алгоритма ЛевенбергаМарквардта [21] оценивались эффективные толщины пленок графена, а также буферного и интеркалированного слоев на разных стадиях формирования системы. Полученные результаты показаны в таблице. Из нее видно, что с увеличением дозы интеркалирования эффективная толщина буферного слоя монотонно снижается (слой становится не сплошным), а сам он фактически исчезает после интеркалирования $0.1 \mathrm{~nm} \mathrm{Si}$. В то же время толщина слоя графена, наоборот, значительно возрастает, и это свидетельствует о том, что в ходе интеркалирования буферный слой полностью перестраивается в графен.

Интеркалирование графена кобальтом может влиять и на спектры Si $2 p$-электронов, так как при высоких температурах атомы Со могут химически взаимодействовать с карбидом кремния. При температуре $450^{\circ} \mathrm{C}$ после интеркалирования $0.6 \mathrm{~nm}$ Со под графеном образуется пленка силицида кобальта толщиной $\sim 0.1 \mathrm{~nm}$, которая почти не растет при дальнейшем интеркалировании графена кобальтом [7]. Последующее интеркалирование данной системы кремнием существенно усиливает линию Si $2 p$ в спектре фотоэлектронов, а также приводит к появлению в ней довольно сложной структуры (рис. 5). Анализ Si $2 p$ спектров, основанный на разложении их на составляющие, позволяет получать ценную информацию о силицидных фазах, формирующихся под графеном в процессе интеркалирования [10,11].

В первом из спектров, представленных на рис. 5, $a$, который был измерен после интеркалирования $0.1 \mathrm{~nm} \mathrm{Si}$, можно выделить три спин-орбитальных дублета, что указывает на наличие трех групп атомов кремния с различным химическим окружением. Основной вклад в спектр вносит компонента $A$, энергия связи которой равна $99.6 \mathrm{eV}$. Энергии двух других мод $B$ и $C$ равны 99.3 и $99.1 \mathrm{eV}$, соответственно. Значения энергии для двух этих мод хорошо согласуются со значениями, приведенными в $[8,9]$. Компонента $C$ усиливается при уменьшении энергии фотонов [8], что позволяет связать eе $\mathrm{c}$ поверхностной фазой силицида кобальта $\mathrm{Co}_{3} \mathrm{Si}$. Компонента $B$ с более высокой энергией связи соответствует атомам кремния, находящимся в глубине образца. Интеркалирование атомов $\mathrm{Si}$ под графен и их диффузия в пленку кобальта приводит к образованию твердого раствора $\mathrm{Co}-\mathrm{Si}$ с концентрацией $\mathrm{Si}$ близкой к пределу растворимости кремния в кобальте (около 20 ат.\% согласно [9]). Что же касается моды $A$ $(99.6 \mathrm{eV})$, которая не обнаруживалась в работах $[8,9]$, мы полагаем, что она соответствует силициду CoSi, так как компонента с данной энергией связи ранее наблюдалась при образовании именно этого силицида $[22,23]$.

Увеличение количества интеркалированного кремния приводит к обогащению сформированных под графеном силицидов кобальта кремнием. Для синтеза ферромагнитных фаз $\mathrm{Co}-\mathrm{Si}$ и $\mathrm{Co}_{3} \mathrm{Si}$ графен следует интеркалировать кобальтом. Поэтому на следующем этапе эксперимента на образец, нагретый до $450^{\circ} \mathrm{C}$, дополнительно наносился кобальт. Из рис. 5, $с$ видно, что интеркалирование $0.3 \mathrm{~nm} \mathrm{Co}$, действительно, привело к существенному снижению интенсивности мод $A$ и $C$, и усилению моды $B$, что свидетельствует о перестройке слоев силицидов и увеличении толщины пленки $\mathrm{Co}_{3} \mathrm{Si}$.

Одним из возможных способов изменения состава и толщины пленок силицидов кобальта под графеном является отжиг образцов при более высоких температурах, чем те, при которых проводилось интеркалирование. В качестве иллюстрации на рис. $5, b$ показаны спектры, полученные после отжига образца при температуре $600^{\circ} \mathrm{C}$. Видно, что проведенный отжиг оказал существенное влияние на $\mathrm{Si} 2 p$ спектр, изменив относительные интенсивности разных мод. Кроме того, он привел к уменьшению ширина моды $B$, соответствующей поверхностному силициду кобальта, что говорит об упорядочении кристаллической структуры данной фазы. Дальнейшее повышение температуры отжига до $850^{\circ} \mathrm{C}$, проведенное после дополнительного интеркалирования графена кобальтом, усилило процесс пере- 


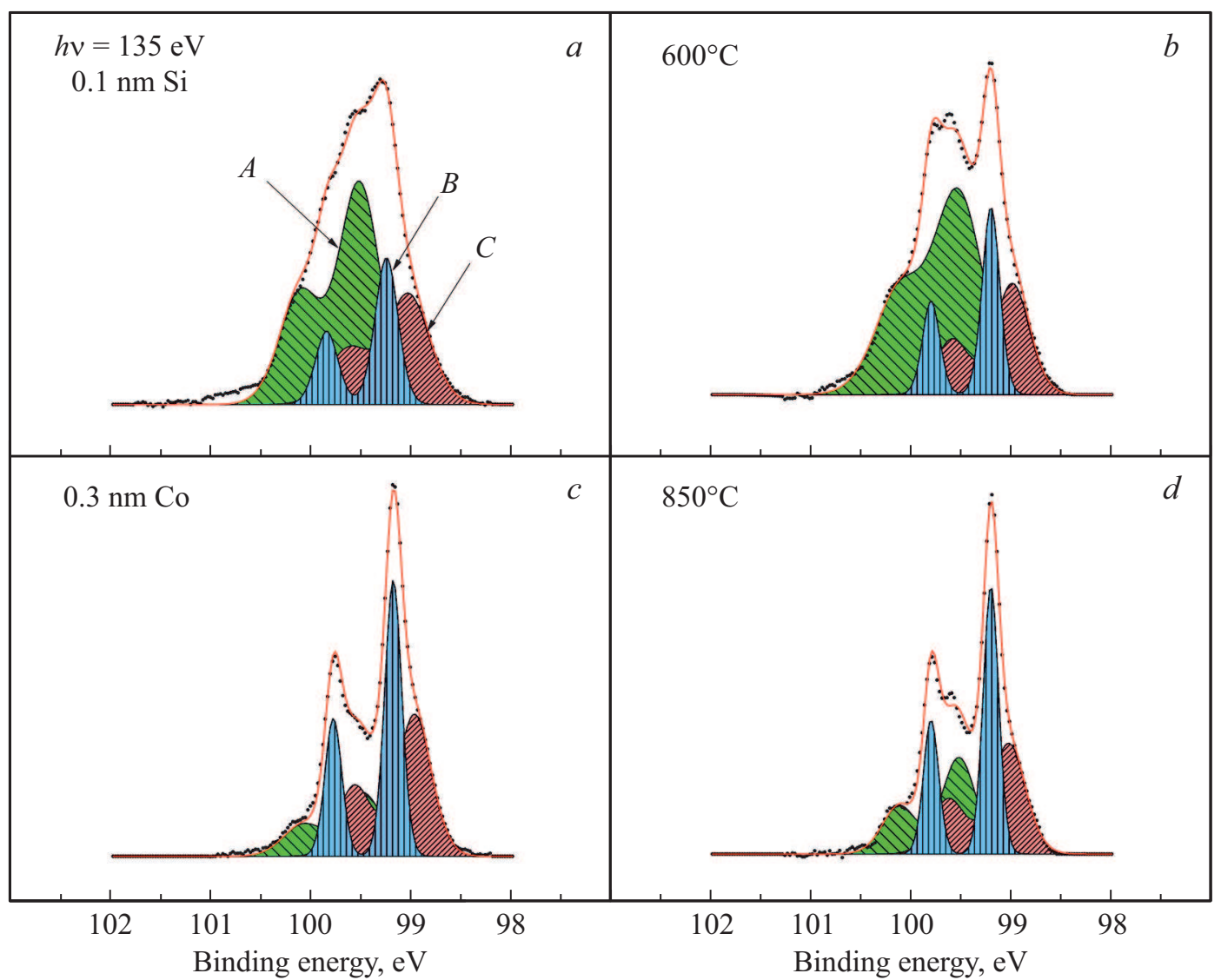

Рис. 5. Спектры Si $2 p$, измеренные на разных стадиях процесса интеркалирования графена кобальтом и кремнием при энергии фотонов $135 \mathrm{eV}$, и результаты их разложения на составляющие.

стройки слоев силицидов богатых кремнием в силицид $\mathrm{Co}_{3} \mathrm{Si}$ (рис. $5, d$ ). Таким образом, изменяя количество интеркалированного кобальта и кремния, а также температуру отжига образца, можно варьировать состав и толщину пленок силицидов кобальта, синтезируемых под графеном.

\section{3. Исследование интеркалированных образцов еx situ}

На рис. 6, $a$ представлен массив спектров КРС, а на рис. $6, b$ указана карта распределения FWHM линии $2 D$, которые были получены в результате сканирования области $10 \times 10 \mu \mathrm{m}$ в центре образца после интеркалирования кобальта и кремния и финального отжига до $850^{\circ} \mathrm{C}$. Наряду с линиями $G$ и $2 D$, в спектрах КРС образца возникает ,дефектная“ линия $D$, по интенсивности сравнимая с линией $G$, а FWHM всех упомянутых линий существенно возрастает. Отношение интенсивностей линий $D$ и $G\left(I_{D} / I_{G}\right)$ составляет $\sim 1$, при этом FWHM линии $G$ в среднем составляет около $35 \mathrm{~cm}^{-1}$, что существенно выше, чем значение этого параметpa $\left(\sim 15 \mathrm{~cm}^{-1}\right)$, характерное для высококачественного графена на $\mathrm{SiC}$. Можно предположить, что появление линии $D$ обусловлено наличием точечных дефектов [24].
Их концентрацию можно оценить по формуле [25]:

$$
n_{D}=\frac{4.3 \cdot 10^{13}}{E_{L}^{4}}\left(\frac{I_{D}}{I_{G}}\right)^{-1}
$$

В нашем случае концентрация точечных дефектов составляет приблизительно $1.5 \cdot 10^{12} \mathrm{~cm}^{-2}$.

Форма $2 D$-линии в образце после интеркалирования значительно изменилась - если в исходном образце она в основном аппроксимировалась одиночным контуром Лоренца, то в большинстве спектров интеркалированного образца ее форма описывается огибающей четырех контуров Лоренца. При этом FWHM линии $2 D$ существенно выше, чем характерная для высококачественного двуслойного графена $\left(\sim 50 \mathrm{~cm}^{-1}\right)$ и варьируется от 85 до $120 \mathrm{~cm}^{-1}$. Подобная форма $2 D$-линии может возникнуть, если предположить, что в результате обработки произошло интеркалирование графена кобальтом или кремнием, в результате чего буферный слой превратился во второй слой графена с наличием существенного количества структурных дефектов. Такой процесс должен вести к нарушению ковалентных связей между буферным слоем и подложкой $\mathrm{SiC}$ и, как следствие, к значительному уменьшению деформации в графеновой пленке. 


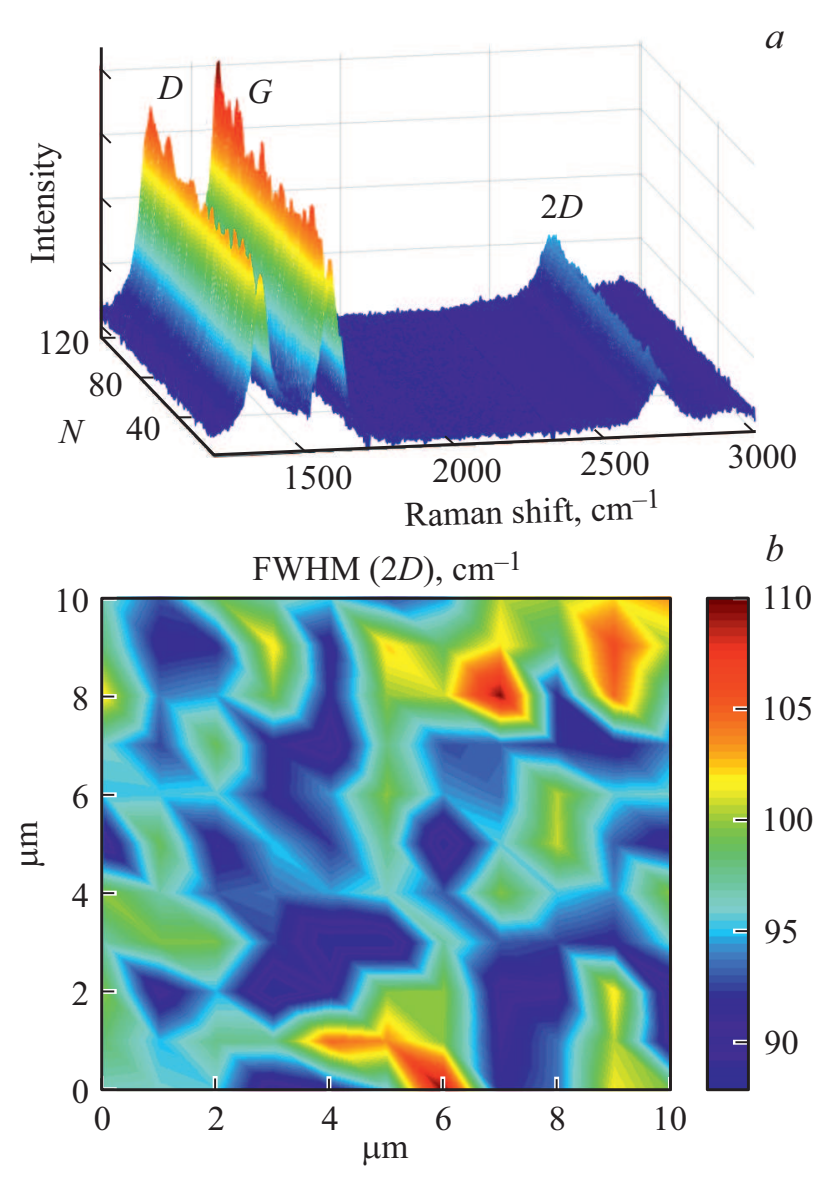

Рис. 6. Массив спектров КРС графена после интеркалирования $(a)$ и карта распределения FWHM линии $2 D(b)$.

На рис. 7, $b$ представлены результаты анализа положения линий $G$ и $2 D$ в массивах спектров, изображенных на рис. $1, a$ и $6, a$. На положение линий $G$ и $2 D$ в спектре КРС графена могут оказывать влияние сразу несколько факторов. Наиболее существенными из них являются концентрация носителей заряда и величина деформации. Совместный анализ положения линий $G$ и $2 D$ в предположении, что на них оказывают влияние только факторы деформации и концентрации носителей заряда, позволяет независимо определять значения концентрации носителей заряда и величину деформации [26].

Для графена, выращенного на $\mathrm{Si}$-грани $\mathrm{SiC}$, характерно присутствие двуосной деформации сжатия и электронный тип проводимости [27]. Возникновение двуосной деформации сжатия в слое графена должно приводить к высокочастотному сдвигу линий $G$ и $2 D[28]$. Увеличение концентрации носителей заряда обоих знаков также приводит к высокочастотному сдвигу линии $\mathrm{G}$, однако, увеличение концентрации электронов вплоть до значения $3 \cdot 10^{13} \mathrm{~cm}^{-1}$ не приводит к существенному сдвигу линии $2 D[29]$. Таким образом, оценить концентрацию носителей и величину двуосной деформации в исследуемом образце можно из сдвига линии $G$ относительно ее изначального положения в электрически нейтральном недеформированном графене. Схема разделения вкладов деформации и легирования в сдвиг линии $G$ показана на рис. $7, a$.

На рис. 7, $b$ приводится откорректированная с учетом скорости Ферми в графене на $\mathrm{SiC}$ [30] корреляционная зависимость между линиями $G$ и $2 D$ для электрически нейтрального графена в условиях двуосной деформации. Данные о корреляции между положениями линий $G$ и $2 D$ для образца до обработки представлены на этом же рисунке в виде массива красных треугольников. Оцененная из этих данных средняя величина двуосной деформации в слое графена составила $\varepsilon_{\|}=-(0.25 \pm 0.05) \%$ (знак минус соответствует деформации сжатия) а средняя величина концентрации электронов $n_{e}(6.0 \pm 0.6) \cdot 10^{12} \mathrm{~cm}^{-2}$.

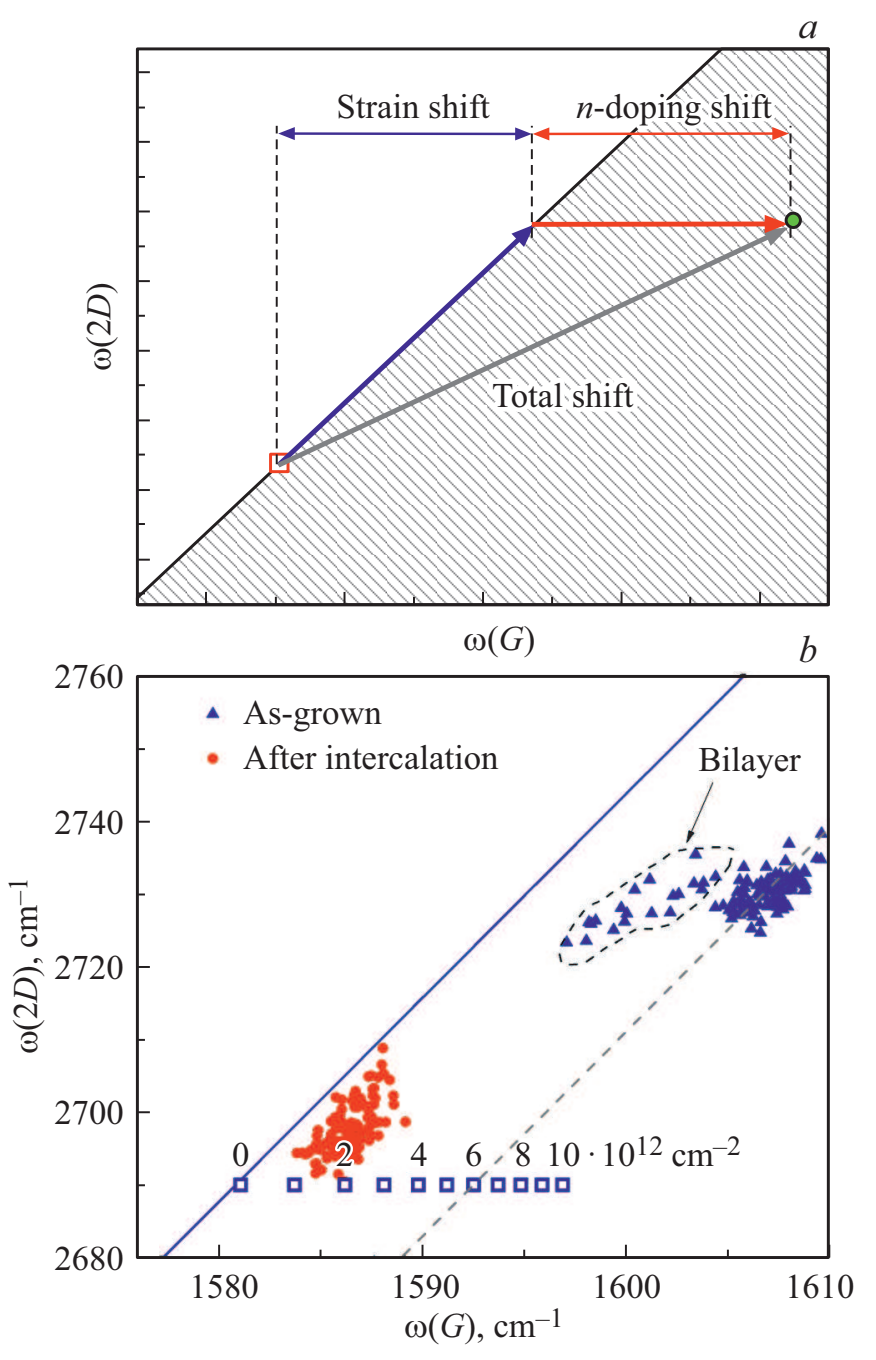

Рис. 7. Схема разделения вкладов деформации и электронного легирования в сдвиг линии $G(a)$. Корреляционная зависимость между линиями $G$ и $2 D$ для электрически нейтрального графена на $\mathrm{SiC}$ в условиях двуосной деформации (сплошная линия). Красным квадратом обозначено положение линий $G$ и $2 D$ в электрически нейтральном недеформированном графене. Данные о корреляции между положениями линий $G$ и $2 D$ для исходного и интеркалированного графена, полученные при сканировании области $10 \times 10 \mu \mathrm{m}^{2}$ (символы) $(b)$. 


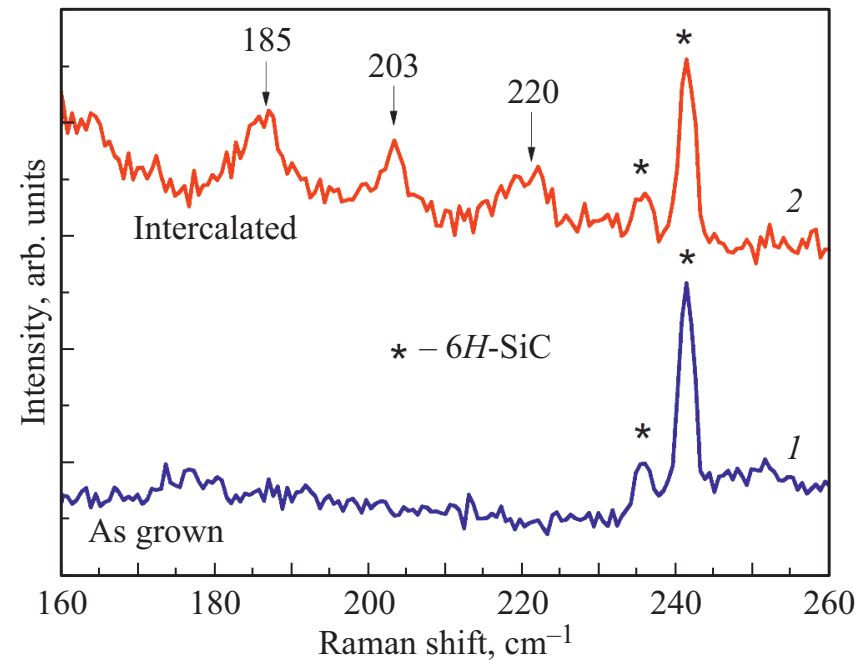

Рис. 8. Спектры КРС образца до (1) и после (2) интенкалирования Со и $\mathrm{Si}$, измеренные в диапазоне $160-260 \mathrm{~cm}^{-1}$.

Данные о поведении линий $G$ и $2 D$ с изменением концентрации электронов в многослойном графене отсутствуют в литературе, поэтому оценить концентрацию электронов в образце после интеркалирования, который представляет собой преимущественно двухслойный графен, достаточно сложно. Надежные данные о коэффициенте деформационного сдвига линии $2 D$ для многослойного графена, также отсутствуют в литературе. Однако, с использованием имеющихся данных для однослойного графена [28] можно приблизительно оценить величину деформации в образце после обработки, которая составила $\varepsilon_{\|}=(0.05 \pm 0.02) \%$. Отсюда следует, что после интеркалирования в результате отрыва слоя графена от подложки вместо достаточно сильной $(-0.25 \%)$ деформации сжатия, характерной для графена на $\mathrm{SiC}$, возникла слабая $(0.05 \%)$ деформация растяжения. Наряду с изменением формы и ширины линии $2 D$, это является еще одним подтверждением интеркалирования графена кобальтом и кремнием.

На рис. 8 изображены спектры КРС образца до и после интеркалирования, измеренные в диапазоне $160-250 \mathrm{~cm}^{-1}$. Кроме спектральных линий, соответствующих сложенным акустическим фононам в $6 \mathrm{H}$ - $\mathrm{SiC}(236$ и $241 \mathrm{~cm}^{-1}$ [31], в спектре образца после интеркалирования появились три новые линии. Линии, имеющие частоту 203 и $220 \mathrm{~cm}^{-1}$, согласно литературным данным, можно связать с наличием между графеном и $\mathrm{SiC}$ пленки силицида кобальта $(\mathrm{CoSi})[32]$. Природа линии, имеющей частоту $185 \mathrm{~cm}^{-1}$, до конца не ясна: предположительно, ее появление может быть связано с поверхностной фазой $\mathrm{Co}_{3} \mathrm{Si}$, на наличие которой.указывают данные ФЭС.

\section{4. Заключение}

В настоящей работе экспериментально исследован интеркаляционный синтез силицидов кобальта под графеном, выращенным на поверхности карбида кремния.
Использование комплекса современных методов, включавших ФЭС высокого энергетического разрешения с использованием СИ, ДМЭ, КРС, АСМ и КЗМ позволило выявить эволюцию процессов интеркалирования графена атомами кобальта и кремния при нанесении их на нагретый образец. Установлено, что атомы этих материалов локализуются между буферным слоем и подложкой, что приводит к трансформации буферного слоя и образованию на поверхности $\mathrm{SiC}$ двухслойного графена. Чередование интеркалирования кобальта и кремния и последующий отжиг образца приводит к образованию под двухслойным графеном твердого раствора кремния в кобальте, силицида $\mathrm{CoSi}$ и поверхностной силицидной фазы $\mathrm{Co}_{3} \mathrm{Si}$. Изменяя количество интеркалируемых материалов и температуру образца, можно менять толщину и состав формируемых пленок. Синтезированные силициды при этом защищены графеном от воздействия окружающей среды.

\section{Благодарности}

Авторы благодарят Российско-Германскую лабораторию на BESSY II и Helmholtz-Zentrum Berlin за возможность использования синхротронного излучения.

\section{Конфликт интересов}

Авторы заявляют, что у них нет конфликта интересов.

\section{Список литературы}

[1] H. Yang, G. Chen, A.A.C. Cotta, A.T. N'Diaye, S.A. Nikolaev, E.A. Soares, W.A.A. Macedo, K. Liu, A.K. Schmid, A. Fert, M. Chshiev. Nature Mater. 17, 605 (2018).

[2] K.V. Emtsev, A. Bostwick, K. Horn, J. Jobst, G.L. Kellogg, L. Ley, J.L. McChesney, T. Ohta, S.A. Reshanov, J. Röhrl, E. Rotenberg, A.K. Schmid, D. Waldmann, H.B. Weber, T. Seyller. Nature Mater. 8, 203 (2009).

[3] G.R. Yazdi, T. Iakimov, R. Yakimova. Crystals 6, 53 (2016).

[4] S.J. Sung, J.W. Yang, P.R. Lee, J.G. Kim, M.T. Ryu, H.M. Park, G. Lee, C.C. Hwang, K.S. Kim, J.S. Kim, J.W. Chung. Nanoscale 6, 382 (2014).

[5] Y. Zhang, H. Zhang, Y. Cai, J. Song, P. He. Nanotechnology 28, 075701 (2017).

[6] М.В. Гомоюнова, Г.С. Гребенюк, В.Ю. Давыдов, И.А. Ермаков, И.А. Елисеев, А.А. Лебедев, С.П. Лебедев, Е.Ю. Лобанова, А.Н. Смирнов, Д.А. Смирнов, И.И. Пронин. ФТТ 60, 1423 (2018).

[7] Г.С. Гребенюк, Е.Ю. Лобанова, Д.А. Смирнов, И.А. Елисеев, А.В. Зубов, А.Н. Смирнов, С.П. Лебедев, В.Ю. Давыдов, А.А. Лебедев, И.И. Пронин. ФТТ 61, 1374 (2019).

[8] O. Vilkov, A. Fedorov, D. Usachev, L.V. Yashina, A.V. Generalov, K. Borygina, N.I. Verbitskiy, A. Grüneis, D.V. Vyalikh. Sci. Rep. 3, 2168 (2013).

[9] D.Yu. Usachov, A.V. Fedorov, O.Yu. Vilkov, I.I. Ogorodnikov, M.V. Kuznetsovetal., Phys. Rev. B 97, 085132 (2018).

[10] G.S. Grebenyuk, O.Yu. Vilkov, A.G. Rybkin, M.V. Gomoyunova, B.V. Senkovskiy, D.Yu. Usachov, D.V. Vyalikh, S.L. Molodtsov, I.I. Pronin. Appl. Surf. Sci. 392, 715 (2017). 
[11] G.S. Grebenyuk, S.M. Dunaevsky, E.Yu. Lobanova, D.A. Smirnov, I.I. Pronin. Appl. Surf. Sci. 470, 840 (2019).

[12] Н.В. Агринская, В.А. Березовец, В.И. Козуб, И.С. Котоусова, А.А. Лебедев, С.П. Лебедев, А.А. Ситникова. ФТП 47, 267 (2013).

[13] А.А. Лебедев, С.П. Лебедев, С.Н. Новиков, В.Ю. Давыдов, А.Н. Смирнов, Д.П. Литвин, Ю.Н. Макаров, В.С. Левицкий. ЖТФ 86, 135 (2016).

[14] В.Ю. Давыдов, Д.Ю. Усачёв, С.П. Лебедев, А.Н. Смирнов, В.С. Левицкий, И.А. Елисеев, П.А. Алексеев, М.С. Дунаевский, О.Ю. Вилков, А.Г. Рыбкин, А.А. Лебедев. ФТП 51, 1116 (2017).

[15] F. Fromm, M.H. Oliveira, A. Molina-Sánchez, M. Hundhausen, J.M.J. Lopes, H. Riechert, L. Wirtz, T. Seyller. New J. Phys. 15, 1 (2013).

[16] V. Panchal, R. Pearce, R. Yakimova, A. Tzalenchuk, O. Kazakova. Sci. Rep. 3, 1 (2013).

[17] C. Riedl, C. Coletti, U. Starke. J. Phys. D 43, 374009 (2010).

[18] K.V. Emtsev, F. Speck, T. Seyller, L. Ley. Phys. Rev. B 77, 155303 (2009).

[19] К. Оура, В.Г. Лившиц, А.А. Саранин, А.В. Зотов, М. Катаяма. Введение в физику поверхности. Москва Наука (2006).

[20] S. Tanuma, C.J. Powell, D.R. Penn. Surf. Inter. Analysis, 17, 911 (1991).

[21] J. Pujol. Geophysics (SEG) 72, A47 (2007).

[22] I.I. Pronin, M.V. Gomoyunova, S.M. Solov'ev, O.Yu. Vilkov, D.V. Vyalikh. Phys. Solid State 53, 616 (2011).

[23] M. Gomoyunova, G. Grebenyuk, I. Pronin. Tech. Phys. Lett. 37, 1124 (2011).

[24] L.G. Cançado, M.G. da Silva, E.H.M. Ferreira, F. Hof, K. Kampioti, K. Huang, A. Pénicaud, C.A. Achete, R. B. Capaz, A. Jorio. 2D-Mater 4, 025039 (2017).

[25] A. Jorio, M.M. Lucchese, F. Stavale, E.H.M. Ferreira, M.V.O. Moutinho, R.B. Capaz, C.A. Achete. J. Phys. Condens. Matter. 22, 334204 (2010).

[26] J.E. Lee, G. Ahn, J. Shim, Y.S. Lee, S. Ryu. Nat. Commun. 3, 1024 (2012).

[27] V.Y. Davydov, D.Y. Usachov, S.P. Lebedev, A.N. Smirnov, V.S. Levitskii, I.A. Eliseyev, P.A. Alekseev, M.S. Dunaevskiy, O.Yu. Vilkov, A.G. Rybkin, A.A. Lebedev. Semicond. 51, 1072 (2017).

[28] F. Ding, H. Ji, Y. Chen, A. Herklotz, K. Dörr, Y. Mei, A. Rastelli, O.G. Schmidt. Nano Lett. 10, 3453 (2010).

[29] A. Das, S. Pisana, B. Chakraborty, S. Piscanec, S.K. Saha, U.V. Waghmare, K.S. Novoselov, H.R. Krishnamurthy, A.K. Geim, A.C. Ferrari, A.K. Sood. Nature Nanotechnol. 3, 210 (2008).

[30] I.A. Eliseyev, V.Yu. Davydov, A.N. Smirnov, M.O. Nestoklon, P.A. Dementev, S.P. Lebedev, A.A. Lebedev, A.V. Zubov, S. Mathew, J. Pezoldt, K.A. Bokai, D.Yu. Usachov. Semicond. 14, 1072 (2019).

[31] S. Nakashima, H. Harima. Phys. Status Solidi A 162, 39 (1997).

[32] J. Zhao, L.K. Ballast, T.Z. Hossain, R.E. Trostel, W.C. Bridgman. J. Vac. Sci. Technol. A 18, 1690 (2000).

Редактор К.В. Емиев 